\title{
A longitudinal study of material planning applications in manufacturing companies
}

Patrik Jonsson

\author{
Division of Logistics and Transportation, Chalmers University of Technology, \\ Gothenburg, Sweden, and$$
\text { Stig-Arne Mattsson }
$$ \\ Department of Industrial Management and Logistics, Lund University, Lund, \\ Sweden
}

\begin{abstract}
Purpose - The paper seeks to describe the state-of-the-art, reasons for selecting various material planning methods, and modes of applying methods for initiating inventory replenishment of purchased items. It also identifies trends from 1993 to 2005.

Design/methodology/approach - Empirical survey data are collected from Swedish manufacturing companies in 1993, 1999 and 2005. The MRP, re-order point, fixed interval ordering, run-out time, and Kanban methods are studied.

Findings - MRP is the most commonly used method and its position has strengthened since 1993. A common way of determining parameters such as order quantities and safety stocks is to use judgment and experience. Parameters used in material planning methods are reviewed relatively infrequently. The planning frequency has increased, with daily planning now being typical.

Research limitations/implications - The major limitation is that different data collection techniques were used in 1993 compared with 1999 and 2005. An important research implication is that the state-of-the-art applications differ from theoretically appropriate application modes. The trends are towards less appropriate modes among the most widespread applications.

Practical implications - The frequency of reviewing planning variables is relatively low in industry, and should in most situations be increased. The paper implies that more user-friendly software applications need to be developed and implemented. It could serve as guidelines when designing and developing training and education programs and function as a benchmark.

Originality/value - The paper provides a longitudinal state-of-the-art description of materials planning usage and identifies application modes with positive and negative performance impact.
\end{abstract}

Keywords Materials management, Order systems, Parametric measures, Manufacturing industries

Paper type Research paper

\section{Introduction}

Several different methods for the planning and control of the flow of material in manufacturing companies have been developed over the years and a number of these are used in manufacturing industry. These planning methods are based on different principles but all provide essentially the same type of support.

Even though they are designed to provide the same type of support, they vary in applicability, with the extent to which they can be used in an efficient and effective way mainly dependent on environment. This has been emphasized by several researchers (Berry and Hill, 1992; Schroeder et al., 1995; Newman and Sridharan, 1995;

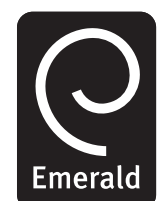

International Journal of Operations \& Production Management Vol. 26 No. 9, 2006 pp. $971-995$ (C) Emerald Group Publishing Limited 0144-3577 DOI 10.1108/01443570610682599 
IJOPM

26,9

972
Jonsson and Mattsson, 2003). Re-order point methods, for example, are component-oriented and primarily designed for items with independent demand. They are normally more appropriate the more standardized the product components are, the longer life cycles they have, and the more stable the demand (Newman and Sridharan, 1995; Jonsson and Mattsson, 2003; Vollmann et al., 2005). Material requirements planning (MRP) is a generally applicable method. It works reasonably well in all manufacturing environments, not least because of its strength in planning items with dependent demand. However, its major strength is in situations with complex standardized products or product options, long manufacturing lead times, and items with time variations and uneven demand (Plenert, 1999; Jonsson and Mattsson, 2003). Kanban is a re-order point method that works best with a regular and steady demand, where the products have a simple and flat bill of material and short lead times together with small order quantities (Gianque and Sawaya, 1992).

As well as by matching methods to specific environments, planning performance also depends on how the methods are applied within the principles they are designed for. Extensive research has been conducted on the principles on which various material planning methods are built and even more on the technical and computational issues relating to them (Vollmann et al., 2005). Less effort has been spent on finding out how to apply them in order to obtain as efficient and effective material flows as possible. All material planning could be conducted without support from enterprise resource planning (ERP) software or other supporting planning and control software. However, the functionality supported by software and the way it is used could affect the possibility of successfully applying a material planning method. ERP is here defined in accordance with Bendoly and Jacobs (2004) as an integrated software approach used to manage the transactions and track the status of a firm's day to day activities. The ERP system is thus the vehicle through which different activities are accomplished (Jacobs and Bendoly, 2003). Most ERP systems include functional support for accomplishing material planning with different planning methods. Jonsson and Mattsson (2005) showed that, compared to low performing users, high performing MRP users-based lead-time determination on quantitative calculations in the ERP systems or monitored actual time to a greater extent. High performing users also reviewed lead times and safety mechanisms more frequently and used daily planning rather than the weekly planning of low performing users. High performing re-order point users calculated the re-order point as the demand during the lead time plus a safety stock; in contrast, low performing users-based re-order point determination on experience and judgment. High performers also reviewed the re-order points more frequently. Consequently, this study shows that the high performing material planning users work more analytically and with higher review frequency compared to the low performing users. This can partly be accomplished by more actively using the functionality of the ERP system.

Considering that the planning environment and the way a material planning method is applied have a major influence on how efficiently and effectively it can be used, it is interesting to examine further which material planning methods companies use and how they use them. Several studies (McLaughlin et al., 1994; Roberts and Barrar, 1992) have suggested that practitioners have not done well in applying the models and functionality that are available to them. Thus, this knowledge is important. Most empirical studies covering the use of methods are relatively old (Davis, 1975; Newman and Sridharan, 1992). Most studies focus on a few material planning methods 
and none is longitudinal and identifies trends. Therefore, a description of the state of the art and recent trends in material planning practice would be an important input in identifying training and education needs, developing more user friendly methods and software, and to serve as a guide for choosing and applying methods.

The objective of the paper is to describe the state of the art, reasons for selecting various material planning methods, and modes of applying methods for the initiation of inventory replenishment of purchased items. It is also to identify trends from 1993 to 2005, comparing the current situation in 2005 with that of 1993 and 1999.

Most of the material planning methods can be used both in the manufacturing and distribution sectors. However, this study covers only manufacturing. The reason is that the current study is a replication of studies conducted in 1993 (Mattsson, 1994) and 1999 (Jonsson and Mattsson, 2002), where only manufacturing companies were examined. The description of present practice covers several methods, but the section on planning parameters and modes of application focuses on the two most commonly used methods: the re-order point and MRP methods.

\section{Usage and modes of applying material planning methods}

Material planning can be seen as a tactical planning level. It concerns balancing supply and demand and in this respect deals with the initiation, control, and monitoring of manufacturing and purchasing orders in order to maintain an uninterrupted material flow and value-adding activity in manufacturing. The two basic questions to address in material planning are "When to order/deliver?" and "How much to order?" - i.e. one time-related and one quantity-related question.

Some of the best known and widely used material planning methods are re-order point, fixed interval ordering, run-out time planning, MRP, and Kanban (Vollmann et al., 2005; Jonsson and Mattsson, 2002) methods. These methods are included in this study. They all answer the two basic material planning questions above, however, they can be applied in various ways.

The material planning methods use specific mechanisms to determine the time and quantity-related questions and the uncertainty considerations related to balancing supply and demand. The quantity mechanisms are more or less the same for all methods, but the timing mechanisms are specific to each method.

Consequently, as well as choosing a method that is appropriate for its context, it also needs to be properly applied, for example, determining and reviewing planning parameters in "correct" ways. The main types of planning parameters may be related to lot sizing, safety mechanisms, and lead times. The planning frequency, replanning strategies, etc. may also differ.

\subsection{Use of material planning methods}

A number of surveys have examined the use of material planning methods. Davis (1975) conducted a survey to find out to what extent re-order points, MRP planning, and methods based on intuition are used in US industry. About 43 percent of the studied companies used MRP and 36 percent used re-order points. The study is now almost 30 years old and thus does not tell us anything about current use of material planning methods. A similar but more recent US study was conducted by Newman and Sridharan (1992), covering re-order points, MRP, Kanban, and OPT. About 56 percent of the studied companies used MRP, 22 percent used re-order points, and 8 percent

\section{Material \\ planning \\ applications}

973 
IJOPM

26,9

974 used Kanban. In the study by Cerveny and Scott (1989) of six different industries, 60 percent were MRP users. White et al. (1999) showed that Kanban investments were more advanced in large manufacturing companies with automated and repetitive processes. Osteryoung et al. (1986) concluded that a majority of firms used re-order points for finished goods inventories rather than for work in process and raw materials. Rabinovich and Evers (2002), on the other hand, found in their survey that MRP was significantly more important than Kanban and re-order points in raw material inventories, and that both MRP and Kanban were significantly more important than re-order points in controlling work in progress and finished goods inventories. Other, less extensive studies of the use of material planning methods include, for example, Code (1993), who examined the extent of MRP and Kanban in the UK, Moras and Dick (1992) who studied the use of Kanban, and Im (1989) who examined the use of re-order points, MRP, and Kanban in companies that had recently implemented just-in-time manufacturing. A conclusion of several of these studies is that MRP has replaced re-order points over time.

Anderson et al. (1982) presented findings on how frequently MRP was run, how lot sizing was carried out, and what bucket sizes were used. Similar studies, though with a more narrow scope, have been published by LaForge and Sturr (1986) and Hadock and Hubicki (1989). Other interesting and related studies are, for example, those conducted by Ledbetter and Cox (1977) and Ford et al. (1987). They examined the use of operations research models in the material planning process, concluding that there is a trend towards less frequent use of OR models in the planning process. About 90 percent of the studied companies used OR models in 1964, compared to 44 percent in 1985.

\subsection{Lot size determination}

Determining order quantities is basically an issue of balancing ordering costs and inventory carrying costs. Different categories of methods to accomplish such a balance may be identified. One refers to methods where the order quantity is made equal to the direct requirement (lot-for-lot), i.e. lot sizing is not carried out. Another refers to methods based on general judgment and intuition, often considered as based on experience. A third category includes methods where the order quantity is calculated using some kind of cost estimation. Here, we could separate fixed optimal order quantity calculations (e.g. EOQ) from dynamic optimal order quantity calculation (Huang, 2000). EOQ is often criticized, but a study by McLaughlin et al. (1994) showed that 28 percent of respondents used EOQ for determining production or purchasing quantities. The approaches to determining the order quantity have a number of different characteristics that may impact on user satisfaction and operative performance. Several studies indicate the performance impact of order quantities: Enns (1999) showed the impact of various fixed order quantities on utilization, work in process, and meeting due dates. The results emphasized the importance of selecting proper batch sizes in MRP. Wemmerlöv and Whybark (1984) showed that dynamic lot-sizing models resulted in higher overall performances compared to other models.

The size of the order quantity is influenced by the current requirements. This means that in order to maintain as optimal order quantities as possible, they must be reviewed periodically. How often this should be is an issue of balancing the cost of review with the benefits of maintaining them closer to the optimum. Experience-based quantities 
are normally more time consuming and costly to review than calculation-based quantities. However, calculation-based quantities are more dependent on the quality of the basic data in order to give reliable measures.

\section{Material planning applications}

\subsection{Safety mechanism determination}

To protect the material flow from disruptions due to uncertainties in demand and supply, various safety mechanisms can be applied in all of the examined material planning methods. The uncertainty in supply and demand can basically be managed in two ways - by adding quantity buffers (i.e. using safety stock) or by adding time buffers (safety time). Whybark and Williams (1976) used simulation studies to conclude that there are strong preferences for using safety lead times in MRP where demand or supply timing uncertainty exists, and using safety stocks where there is uncertainty in either the demand or supply quantity. Similar studies and findings relating to MRP (Molinder, 1997) and periodic review methods (Benton, 1991) have been carried out.

Consequently, safety mechanisms can be determined in various ways. Ideally, they should be determined by balancing inventory carrying costs against shortage costs or service levels. Alternative ways of determining safety mechanisms are to use experience or to add a fixed percentage to the lead-time demand. Both these approaches are less optimal under normal circumstances, especially the experience-based approach which cannot automatically be updated and is therefore more costly to review.

\subsection{Lead-time determination}

Accurate lead times are very important for all material planning methods. This is, for instance, the case when calculating re-order points in re-order point methods, comparing run-out times with replenishment lead times in run-out time planning, and when off-setting start dates in MRP. Lead times can be based on experience, calculations in the ERP system, or monitored actual time. Experience-based lead times have the same drawbacks as experience-based order quantities and safety stocks. Analytically calculating fixed lead times has been identified among MRP users as a significantly important strategy for achieving high planning performance (Jonsson and Mattsson, 2005). There is also a difference between fixed and dynamic lead times. Zijm and Buitenhek (1996) discussed the problem with fixed lead times in MRP and compared it with workload-dependent lead times which resulted in significantly higher performance.

\subsection{Parameter review, planning frequency and replanning}

The modes of determining order quantities, safety mechanisms, and lead times consequently affect the possibility of obtaining accurate and appropriate measures. The frequency of reviewing the parameters also affects the dynamics of the methods and thereby the operative performance of the material planning. A study by Jonsson and Mattsson (2005) shows that a higher review frequency of order points in re-order point methods and lead times and safety stocks in MRP have significant positive performance impacts. However, frequent adjustments could also have an augmented effect, often referred to as system nervousness. One way of decreasing the nervousness would be to work with longer planning periods and by freezing time fences (Tang and Grubbström, 2002). However, longer planning horizons may actually worsen MRP 
IJOPM

26,9

976 performance in a demand uncertainty situation but improve its performance in a deterministic case (Zhao and Lee, 1993). Thus, the review frequency is especially important in situations of varying demand and supply.

In addition, the planning frequency and ability of the method to automatically replan orders may have the same impact on planning performance. In addition to these general modes of applying methods, there are method-specific modes, for example determination of order points in the re-order point method and the number of cards in the Kanban method. In particular, the planning frequency and determining the order point as the lead-time demand plus a safety stock rather than by an experience-based fixed quantity have been identified as important for planning performance (Jonsson and Mattsson, 2005).

\section{Methodology}

The analysis is conducted in two stages and is based on empirical data from surveys in 1993, 1999, and 2005:

(1) description and comparison of usage trends for material planning methods in 1993, 1999, and 2005; and

(2) description and comparison of the modes of applying re-order point and MRP methods in 1993, 1999, and 2005.

\subsection{The survey instrument}

There are two types of variables and related sets of measures in this study, one for each analysis. The first measures the use of the respective material planning method; the second describes the mode of application of a specific planning method. The classifications used and criteria measured follow the general manufacturing planning and control definitions (Vollmann et al., 2005). The survey instrument used for measuring the variables was developed for the 1993 study (Mattsson, 1994), and was further developed in the 1999 study (Jonsson and Mattsson, 2002). It has thus been tested and used in two studies preceding the 2005 survey.

\subsection{Planning method measures}

In evaluating the use of planning methods, respondents were given four alternatives:

(1) the method is not used;

(2) the method is used as a complement;

(3) the method is used as the (or a) main method; and

(4) do not know.

Respondents marking alternatives 2 or 3 were coded as users. Main methods were identified as the method used for the majority of items.

\subsection{Modes of application measures}

The modes of application for the studied materials planning methods were measured in terms of choice of lot-sizing methods, ways of considering uncertainties, level of analytical determination of order quantity, level of analytical determination of re-order points, level of analytical determination of safety stocks and safety times, level of analytical determination of lead times, level of automatic replanning, number of changes to planned orders, review frequency of order quantities, review frequency of 
safety stocks and safety times, review frequency of lead times, and planning frequencies. All variables were measured on ordinal scales except for the choice of lot-sizing methods and ways of considering uncertainties, which were measured on nominal scales.

\subsection{The selection and data collection}

Data collection for the 1993 study was by personal interviews, while mailed surveys were used for the 1999 and 2005 studies. Table I shows the characteristics of the respondents. The 82 companies in the 1993 study were selected by convenience sampling (Bryman, 2004), i.e. selected from personal contacts with companies. Data collection was then by personal interviews at the companies.

The mailed surveys were sent to members of manufacturing companies of the Swedish Production and Inventory Management Society (PLAN), an affiliate of APICS. PLAN members are broadly distributed among manufacturing industries in accordance with the average for Swedish manufacturing (i.e. with about half of the companies in mechanical engineering). A reason for sending the questionnaire to PLAN members was that they were thought likely to be interested in manufacturing planning and familiar with the terminology used in the survey. Membership of PLAN is personal. Therefore, the studied companies were not expected to be more advanced users of planning methods compared to the average for Swedish manufacturing. Although several different material planning situations and applications could exist in one company, only one response per company is included in the analysis. Respondents were requested to answer only those sections they were familiar with and to hand the questionnaire to those who were most appropriate for answering particular sections. Therefore, it should be safe to assume that the responses were valid.

In 1999, a mailed paper-based survey was used. It was sent to 380 people representing different companies. About 84 usable responses were received, giving a response rate of 22 percent. In the 2005 study, a web-based survey was conducted. It was e-mailed to people in 573 companies. Of these, 153 responded, which is a response rate of 27 percent. The relatively long length of the questionnaire may explain the comparatively low response rates. About half of the respondents in the two first studies were from the mechanical engineering sector. This proportion was somewhat higher in the 2005 study. There was also a higher proportion of large companies in the 2005 study (Table I). Companies with a turnover below SEK 100 million (equivalent to about $€ 12$ million) or less than 50 employees were defined as small. Those with a

\begin{tabular}{|c|c|c|c|c|c|c|c|}
\hline & \multicolumn{2}{|c|}{2005 study } & \multicolumn{2}{|c|}{1999 study } & \multicolumn{2}{|c|}{1993 study } & \\
\hline & Responses & Percentage & Responses & Percentage & Responses & Percentage & \\
\hline \multicolumn{8}{|l|}{ Size } \\
\hline Small & 13 & 8 & 10 & 13 & 17 & 21 & \\
\hline Medium & 34 & 22 & 26 & 33 & 29 & 35 & \\
\hline Large & 106 & 70 & 42 & 54 & 36 & 44 & \\
\hline \multicolumn{8}{|l|}{ Industry } \\
\hline Food and chemistry & 26 & 17 & 20 & 24 & 18 & 22 & \\
\hline Mechanical engineering & 117 & 76 & 36 & 43 & 47 & 57 & Table I. \\
\hline Other industries & 10 & 7 & 28 & 33 & 17 & 21 & Characteristics of \\
\hline Total & 153 & 100 & 84 & 100 & 82 & 100 & respondents \\
\hline
\end{tabular}

Material planning applications

977 
IJOPM

26,9

978 turnover between SEK 100 million (about $€ 12$ million) and SEK 300 million (about $€ 36$ million) and with more than 50 employees were defined as medium-sized companies.

\subsection{Reliability and validity}

To make it easier to synthesize and analyze the data, only questions with closed reply options were included, with the exception that where there was a risk of not including all relevant reply options, an open alternative was added. This allowed the respondents individual alternatives. To increase the reliability and validity, the questionnaire was pre-tested and some questions adjusted before being finally sent out. As stated above, all respondents were members of PLAN, which should ensure familiarity with planning methods.

The industry and company sizes of the respondents, with a focus on the mechanical engineering industry and an increasing number of large companies, resembled the demographics of Swedish manufacturing in general and is comparable to the demographical distributions in other similar Swedish surveys (Olhager and Seldin, 2004). To increase the response rate and to identify the reasons for non-responses, potential respondents of the 1999 and 2005 surveys received a reminder by phone. Addressees were also requested to reply if they did not intend to complete the questionnaire. Four reasons for not answering were given. In total 82 reasons for non-responses were given: 40 (49 percent) stated that their company had no production or inventories and was thus not relevant for the study; 20 (24 percent) did not have the necessary knowledge to answer accurately; 17 (21 percent) did not have enough time or did not wish to complete the questionnaire; and 5 (6 percent) no longer worked for the company. The population could thus be adjusted to 533 companies, which gives an adjusted response rate of 29 percent. If 49 percent of all companies would be irrelevant for the study, then the response rate would be 55 percent. Chi-square tests did not reveal any significant difference between respondents and non-respondents regarding company size or industry in any of the surveys. It should therefore be possible to generalize the findings for most manufacturing industries.

A four-page folder with definitions and descriptions of the methods for material planning was attached to the surveys. This should ensure that the measures were valid and that respondents had the same definitions of the planning methods, further improving the understanding and validity of the study.

Some differences in company size and industry sector of the companies were identified between the 1993, 1999 and 2005 surveys (Table I). The fact that the data sets are not completely homogeneous makes the longitudinal analysis more difficult to conduct. This potential problem was dealt with by testing the significantly changed method usages for companies of different sizes and for companies belonging to different industries, separately. These tests would show if a significantly identified change in method usage could be related to a specific industry or size of company. The different percentages of main method users were compared between companies of various sizes and in different industries, on the 2005 data. Further, the different percentages of companies using various modes of applying the re-order point and MRP methods were compared between small/medium- and large-sized companies, on the 2005 data. These tests would give indications as to whether the use of methods and modes of applying the methods differ between companies of various sizes and between industries, i.e. validating the longitudinal analyses that do not consider size and 
industry differences. The above-mentioned tests of the industry and size impact on method usage and modes of applying methods would improve the validity of the findings. The longitudinal analysis may still contain some weaknesses due to the lack of perfectly homogeneous samples and since the analyses are not restricted to focused fields, like a specific industry, a specific company size, a specific manufacturing process, a specific planning environment, etc.

\subsection{The statistical tests}

The level of measurement of the questions differed between nominal, ordinal and interval scales. Therefore, various statistical methods were used to analyze the data. Selection of the methods followed the guidelines of, for example, Siegel and Castellan (1988) and Hair et al. (1998). For the scales that were of nominal type, statistical analysis was carried out using chi-square statistics, including residual tests. Kruskal-Wallis one-way analysis of variance and pair-wise Mann-Whitney tests were used for scales of ordinal type. ANOVA was used for scales of interval type.

\section{Findings and discussion}

\subsection{The use of material planning methods}

The percentage of companies using any of the five material planning methods to some extent is presented in Table II. The re-order point and MRP methods are by far the most common material planning methods over the period. However, the use of Kanban increased significantly between 1993 and 1999. This is in line with expectations: from the end of the 1980s, many companies applied a just-in-time/lean production approach and implemented more customer-order-oriented production as a way of increasing efficiency and competitiveness. Applying Kanban is one way of doing this. The use of re-order point methods was more or less constant over the period, while the use of MRP increased significantly between 1993 and 1999. MRP is now the most common method.

\begin{tabular}{lccc}
\hline Material planning methods used & 2005 & 1999 & 1993 \\
\hline Re-order point method & $73\left(33^{*}\right)$ & $83\left(22^{*}\right)$ & $71(33)$ \\
Periodic replenishment method & $12(7)$ & N/A & N/A \\
Run-out time method & $26(13)$ & $31^{*}\left(14^{*}\right)$ & $10(2)$ \\
Material requirements planning method & $84(75)$ & $82^{*}\left(75^{*}\right)$ & $59(44)$ \\
Kanban method & $41(13)$ & $51^{*}\left(11^{*}\right)$ & $9(1)$ \\
Number of methods used in parallel & $2.43(0.90)$ & $2.54(0.99)$ & $2.39(1.05)$ \\
Motives when selecting methods & 19 & 19 & 26 \\
Do not know/the method has always been used & 1 & 6 & 4 \\
No special reason & 26 & 31 & 18 \\
The method was available in the ERP system & 5 & 3 & 7 \\
The method was recommended by a consultant & 9 & 8 & 4 \\
The method is used in other companies I know & 40 & 33 & 41 \\
The selection is based on analysis and assessment & & &
\end{tabular}

Notes: Material planning methods used: numbers within parentheses indicate the percentage of companies using the method as "main method", i.e. method used for the majority of the items and/or for the most important item. More than one method could be main method. * Indicates cell that differs significantly $(p<0.05)$ from expected values (compared to the previous year) in Chi-square tests. Number of methods used in parallel: figures indicate mean (standard deviation)

\section{Material planning applications}

979 
IJOPM

26,9

980
When analyzing the "main methods," it is even clearer that MRP is the dominant method. Its position as the primary method in industry was reinforced during the 1990 s and the beginning of the 2000s. In 2005, 75 percent of the companies used MRP as their main method compared to 33 percent using re-order point as a main method (respondents could mark more than one "main" method).

A possible reason for the heavy use of MRP is the increased use of standard ERP systems including MRP functionality. The increased exchange of delivery schedules between customers and suppliers could be another reason for the heavy MRP usage, since the MRP method is almost a necessity for the generation of delivery schedules.

For the significantly changed method usages (those marked with * in Table II), the changes were also studied for small/medium and large companies, and for food/chemical and mechanical industry, respectively. Significant correlations, on the $p<0.05$ level, between size of the company and changed usage of method were identified for main method users of the re-order point method (with a significant increase among small- and medium-sized companies between 1999 and 2005) and for users of MRP (with a significant increase among small- and medium-sized companies between 1993 and 1999). Significant correlations, on the $p<0.05$ level, between industry and changed usage of method were identified for the food and chemical industries with significantly increased usage of the run-out time, MRP and Kanban methods between 1993 and 1999 .

Table III shows the use of main methods in companies of various sizes and in different industries in the 2005 study. 62 percent of the small- and medium-sized companies and 75 percent of the large companies used MRP as a main method. The usage of re-order points as a main method was different. About 47 percent of the smalland medium-sized companies and 26 percent of the large companies used that method as the main method. We excluded methods with very few main method users and conducted a chi-square test between small/medium- and large-sized re-order point and MRP users only (i.e. a $2 \times 2$ table), compared to an evenly distributed usage among small and medium- and large-sized firms, respectively. The difference was significant at the $p<0.05$ level. The results show that in larger companies, MRP is used more than re-order point methods and vice versa, a trend that is in line with previous studies (Rabinovich and Evers, 2002). No significantly different usage was identified between industries.

The 2005 sample contains a larger proportion of large companies compared to the 1999 and 1993 samples. This fact makes the comparison of material planning method usage between 2005 and the previous years difficult to conduct. However, the significantly increased MRP usage was identified between 1993 and 1999 when the firm sizes in the samples were relatively homogeneous.

Most companies use several planning methods in parallel. In all three studies the average company used between two and three methods in parallel (Table II). About 44 percent of the companies in the 1993 study used three or more methods. The corresponding percentages in 1999 and 2005 were 51 and 43 percent, respectively.

The motives for selecting particular material planning methods are presented in the lower part of Table II. The figures refer to the percentage of companies citing each of the motives as the basis for selection. The last three alternatives could be considered to be based on some kind of assessment, while the first three are not. Over the whole period from 1993 to 2005 there has been an approximately even spread between using 


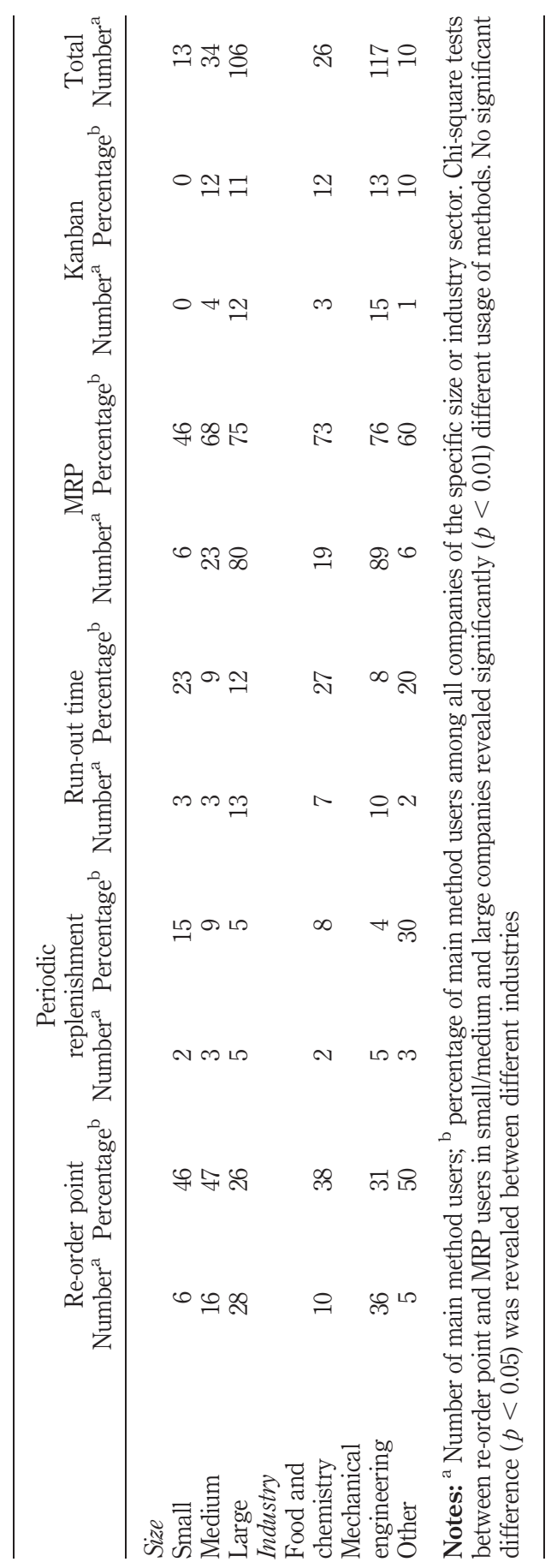

Material
planning
applications

981

Table III.

Number and percentage of companies using method as main method in different types of companies 
IJOPM

26,9

982 and not using some kind of assessment. It is somewhat surprising that experiences of other companies have such low importance for decisions on material planning method, particularly considering that reference visits are very often made when selecting a new ERP system. Exchange of experiences among representatives of different companies and consultants through various types of competence networks and mutual company visits obviously therefore play an insignificant role in selecting a planning method.

\subsection{The modes of application}

Each of the material planning methods included in this study is only completely defined according to the principles it is based on - for example, the way new orders are initiated and the way delivery dates/ordering dates for orders are established. Within the framework of these principles the planning methods can be applied in various ways. Calculation of order quantities, determining lead times and buffering against uncertain demand can for instance be done in a number of ways for each method. To answer the second part of the study objective, i.e. how the various material planning methods have been applied, a number of application-related issues and related questions were included. Applications were studied for the most frequently used methods: re-order point and MRP. Different modes of applications without considering differences in company size or industry are compared between 1993 and 1999, between 1999 and 2005 and between 1993 and 2005. Different modes of applications are also compared between small/medium- and large-sized companies in the 2005 sample.

4.2.1 Lot sizing. Table IV shows the type of lot-sizing methods and review frequencies used for each method.

Lot-for-lot, EOQ, and dynamic optimization methods are the alternatives that allow automatic updating of the ERP system, while the experience-based alternatives do not. The majority of re-order point users (60 percent) and 40 percent of MRP users base

\begin{tabular}{lcccccc}
\hline & ROP & ROP & ROP & MRP & MRP & MRP \\
Lot-sizing method used & 2005 & 1999 & 1993 & 2005 & 1999 & 1993 \\
\hline Lot-for-lot & - & - & - & $24^{\mathrm{a}}$ & 35 & 45 \\
Experienced-based fixed quantity & 29 & 25 & 30 & $11^{*}$ & $13^{*}$ & 34 \\
Experienced-based number of periods covered & 31 & 37 & 40 & 29 & 21 & 25 \\
Economic order quantity (EOQ) & 40 & 33 & 38 & $31^{*}$ & $26^{*}$ & 48 \\
Dynamic optimization method & - & 5 & 7 & 5 & 5 & 7 \\
Other methods & & & & & & 0 \\
Review frequency of lot-sizes & $64^{* a}$ & $46^{*}$ & 33 & $39 *$ & 43 & 55 \\
Once a year or less frequently & 26 & 29 & 28 & 23 & 19 & 45 \\
At least a couple of times per year & 10 & 25 & 40 & 37 & 38 & N/A \\
At each ordering & & & & &
\end{tabular}

Notes: ROP $=$ re-order point method. MRP $=$ material requirements planning method. Differences between 1993, 1999 and 2005 are tested with Chi-square statistics for rows experience-based fixed quantity, Economic order quantity, once a year or less frequently. ${ }^{*}$ Indicates cell that differs significantly $(p<0.05)$ from expected values (compared to the 1993 value) in Chi-square test. ${ }^{\text {a }}$ Indicates cell that differs significantly $(p<0.05)$ from expected value (compared to the 1999 value) in Chi-square test. Tests are conducted separately for ROP and MRP. Mann-Whitney tests of the review frequencies could not reveal any significant difference on the $p<0.05$ level over the years
Table IV.

Percentage of companies using various lot-sizing and re-order point strategies 
lot-sizing decisions on experience. MRP users, however, used experience to a lesser extent in 1999 and 2005 compared to 1993. However, for purchasing items this alternative includes the rule to use a fixed number of pallets or packages, which is a practical method in a number of situations. The use of the EOQ formula decreased significantly among MRP users from 1993 to 1999, but the method is nevertheless very common (31 percent of MRP and 40 percent of re-order point users) in 2005. No significantly different usage of experience based or analytically determined lot sizing method (EOQ or dynamic method) was identified between small/medium- and large-sized companies for the re-order point or MRP method in the 2005 study.

The frequency of reviewing order quantities increased between 1993 and 2005 for MRP, with 55 percent reviewing once a year or less frequently in 1993 and 39 percent in 2005. However, for ROP the corresponding frequency decreased over the same period, with 33 percent reviewing annually or less frequently in 1993, 46 percent in 1999, and 64 percent in 2005 (Table IV). The ROP trend is the reverse of what would be expected in order to improve planning performance. The reason for the less frequent revision of ROP parameters may be that the successive change from ROP to MRP has decreased the efforts spent on ROP revision. Nonetheless, approximately 40-60 percent of the companies review their order quantities once a year or less frequently irrespective of the planning method used. A possible explanation for the relatively low review frequency is that optimization methods for determining order quantities are used by the same low proportion of companies. An advantage of using some kind of optimizing lot-sizing method is that new order quantities can be calculated automatically. Accordingly, there is less work and cost involved in reviewing them frequently. No significantly different review frequency was identified between small/medium- and large-sized companies for the re-order point or MRP methods in the 2005 study.

4.2.2 Ordering mechanisms. In the re-order point method orders are triggered by a re-order point, equivalent to the demand during lead time plus a safety stock. In MRP, orders are triggered by netting and exploding the requirements through the bill of materials. The MRP procedure is standardized and controlled by the ERP system but the re-order point procedure may be carried out in a number of different ways.

Determining re-order point quantities is basically an issue of determining a quantity sufficiently large to cover the requirements during the replenishment lead time plus some safety stock to allow for uncertainty. Two categories of methods for achieving this were included in the study: determination based on experience and judgment, and determination based on some type of calculation. The second alternative is the theoretically most correct, allowing separation of lead time and the uncertainty-related part of the re-order point.

The proportion of companies determining their re-order quantities using some type of calculation and consequently allowing the separation of lead time and uncertainty and automatic revision is no more than 60 percent in the 2005 study (Table V). The review frequency of re-order points is evenly distributed among the companies - from less than once a year to a couple of times per year. The proportion of companies reviewing order points less than once a year increased significantly from 15 percent in 1993 to 22 percent in 1999 and 35 percent in 2005. The fact that the review frequency is decreasing is worth emphasizing since it has been shown to have a negative impact on planning performance (Jonsson and Mattsson, 2005). No significantly different mode of 


\section{IJOPM 26,9}

\section{4}

Table V.

Order point determination and reviewing

\begin{tabular}{llll}
\hline & ROP & ROP & ROP \\
& 2005 & 1999 & 1993 \\
\hline
\end{tabular}

Determination of re-order points

Based on experience and judgment

Calculated as lead-time demand plus safety stock

Other methods

Review frequency of re-order points

Less than once a year

Roughly once a year

At least a couple of times per year

$\begin{array}{ccr}39 & 45 & 32 \\ 60^{\mathrm{a}} & 48^{*} & 66 \\ 1 & 7 & 2 \\ & & \\ 35^{* \mathrm{a}} & 22^{*} & 15 \\ 30 & 39 & 37 \\ 35 & 39 & 48\end{array}$

Notes: Differences between 1993, 1999 and 2005 are tested with Chi-square statistics for rows: calculated as lead time demand plus safety stock, and less than once a year. ${ }^{*}$ Indicates cell that differs significantly $(p<0.05)$ from expected values (compared to the 1993 value) in Chi-square test. ${ }^{\text {a }}$ Indicates cell that differs significantly $(p<0.05)$ from expected value (compared to the 1999 value) in Chi-square test. Mann-Whitney tests of the review frequencies could not identify any significant $(p<0.05)$ level between the years

determining the re-order point or review frequency was identified between small/medium- and large-sized companies in the 2005 study.

Demand data are necessary for calculating order quantities, safety stocks, and order points in the re-order point method. A rough estimation of the demand is also necessary if the determination is based on experience or judgment. Table VI shows that some type of demand forecasting was the most common source of demand data in 1993 and 2005, but that there was a significantly increased use of requirements planning between 1993 and 1999, and that about one quarter of the respondents used requirements planning to generate demand data in 2005 . The majority of re-order point users also use MRP. Therefore, it is somewhat remarkable that there is not a larger proportion of companies using requirements planning to generate demand data. No significantly different source of demand was identified between small/medium- and large-sized companies in the 2005 study.

4.2.3 Safety mechanisms. Uncertainties in supply and demand can be managed in essentially two different ways - by adding quantity buffers, i.e. using a safety stock, or by adding time buffers, i.e. using safety time. The traditional re-order point method uses only safety stocks as the buffering mechanism. Uncertainties in time are normally considered to be more efficiently managed by time-based buffering mechanisms and

\begin{tabular}{lccr}
\hline & ROP & ROP & ROP \\
Source of demand & 2005 & 1999 & 1993 \\
\hline Based on experience and judgment & 13 & 13 & 7 \\
From last year's demand & 18 & 21 & 18 \\
Based on some type of forecasting & $43^{*}$ & $30^{*}$ & 70 \\
Based on requirements calculation & $26^{*}$ & $36^{*}$ & 13
\end{tabular}

Table VI.

Source of demand in the re-order point method
Notes: Differences between 1993, 1999 and 2005 are tested with Chi-square statistics for all rows. *Indicates cell that differs significantly $(p<0.05)$ from expected values (compared to the 1993 value) in Chi-square test. No significant difference $(p<0.05)$ was identified between 2005 and 1999 
uncertainties in quantity by quantity-based buffering mechanisms (Molinder, 1997). Table VII shows that the majority of MRP users have always used safety stocks as the safety mechanism. The use of safety time was significantly lower at all three survey points. The percentage of companies not using safety mechanisms were significantly $(p<0.05)$ higher for small/medium-sized companies compared to large-sized companies in the 2005 study.

Ideally, the determination of safety stock and safety time should be by balancing inventory-carrying costs against shortage costs or service levels. However, in cases where the safety stock is included in the re-order point quantity, this is not possible. The percentage of re-order point companies using this alternative was 21 percent in the 2005 study (Table VIII). The most common method of determining safety stocks in the 2005 study was to calculate them from specified service levels. This is the only alternative providing opportunities to try to balance the size of the inventory against service levels. The use of this alternative has increased significantly since 1999, when experience was the most common method. This trend is important since safety stock determination is one of the parameters with greatest impact on planning performance (Jonsson and Mattsson, 2005). The percentage of companies including safety-stocks in the re-order point was significantly $(p<0.05)$ higher for small/medium-sized companies compared to large-sized companies in the 2005 study.

\begin{tabular}{lccc}
\hline Safety mechanisms & MRP2005 & MRP1999 & MRP1993 \\
\hline Safety stock/safety time not used & 11 & 8 & 13 \\
Safety stock & $54^{\mathrm{a}}$ & $74^{*}$ & 62 \\
Safety time & $29^{\mathrm{a}}$ & $15^{*}$ & 36 \\
Other type of mechanism & 6 & 3 & 11
\end{tabular}

Note: Differences between 1993, 1999 and 2005 are tested with Chi-square statistics for the three first rows. * Indicates cell that differs significantly $(p<0.05)$ from expected values (compared to the 1993 value) in Chi-square test. ${ }^{\text {a }}$ Indicates cell that differs significantly $(p<0.05)$ from expected value (compared to the 1999 value) in Chi-square test. Chi-square tests also revealed that safety stock was used to significantly $(p<0.05)$ greater extent than safety time in all three years

\section{Material planning applications}

985

\begin{tabular}{lccr}
\hline & ROP & ROP & ROP \\
Safety stock determination & 2005 & 1999 & 1993 \\
\hline Safety-stocks included in the re-order point & $21^{* a}$ & $34^{*}$ & 8 \\
Based on judgment and experience & 36 & 47 & 42 \\
Adding a percentage on the lead time requirement & 8 & 8 & 22 \\
Calculated from a specified service level & $34^{*}$ & $11^{*}$ & 28 \\
Other methods & 0 & 0 & 8
\end{tabular}

Notes: Differences between 1993, 1999 and 2005 are tested with Chi-square statistics for rows one, three and four. *Indicates cell that differs significantly $(p<0.05)$ from expected values (compared to

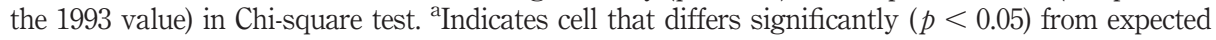
value (compared to the 1999 value) in Chi-square test
Table VII.

Percentage of companies using various safety mechanisms in MRP 
IJOPM

26,9

986

When demand and other conditions in the planning environment are changing, it is desirable to also review the safety stocks as well as safety times. The review frequency of safety mechanisms is about the same as for order quantities (Table IX). The relatively low frequency may, as for review of order quantities, be a consequence of an increase in the use of methods based on judgment and experience rather than some kind of optimization method that is capable of more or less automatically recalculating safety stocks and safety times. As a result, the amount of work involved in reviewing the parameters becomes too extensive to be frequently carried out. No significantly different review frequency was identified between small/medium- and large-sized companies in the 2005 study.

An interesting observation can be made when comparing the frequency of reviewing order quantities and safety stocks. According to the 1993 and 1999 studies, order quantities are reviewed significantly $(p<0.05)$ more often than safety stocks. In 2005 , too, order quantities were reviewed more frequently, though not significantly more. About 60 percent of MRP users reviewed order quantities more frequently than once a year compared to 49 percent for safety stocks. Shortages arising from less accurately determined safety stocks and safety times normally represent more serious problems than deviations from optimal order quantities. Applying a higher review frequency for safety stocks and safety times compared to order quantities could accordingly be expected to be more efficient and effective.

4.2.4 Lead times. This section presents the results for applications relating to lead times. The lead time represents an integrated element of calculating re-order point quantities, and results from the study relating to this have already been presented in previous sections. Accordingly, the presentation here is limited to lead-time issues related to MRP. Three alternative categories of methods for determining lead times have been included in the study. The first is based on general judgment and experience, the second on monitoring actual lead times, and the third on calculations from the routing and work center files in the ERP system. The third alternative can only be used for manufactured items. There is an almost evenly distributed use of the three alternatives since 1993 (Table X). It is somewhat surprising that the alternative of monitoring actual lead times has not increased more over time.

The lead time is one of the most critical parameters in material planning (Jonsson and Mattsson, 2005). High accuracy is thus very important. To accomplish this, lead times have to be reviewed periodically to accurately reflect the current situation. In this case, the same arguments apply as for the review of order quantities - it is an issue of balancing the cost of review with the benefits of more accurate lead times. Manufactured items (M) and purchased items (P) are accounted for separately.

Table IX.

Percentage of companies using various review frequencies of safety stocks

\begin{tabular}{lccc}
\hline Reviewing frequency of safety stocks & MRP 2005 & MRP 1999 & MRP 1993 \\
\hline Less frequently than once a year & 19 & 26 & 24 \\
Roughly once a year & 32 & 38 & 31 \\
At least a couple of times per year & 49 & 36 & 45
\end{tabular}

Notes: Mann-Whitney tests of the review frequency identified significantly $(p<0.05)$ higher review frequencies in 2005 compared to 1999 but there was no significant difference between 1999 and 1993 or between 2005 and 1993 


\begin{tabular}{lcccccc}
\hline & ML & ML & ML & PL & PL & PL \\
Determination of MRP lead times & 2005 & 1999 & 1993 & 2005 & 1999 & 1993 \\
\hline Based on general judgment and experience & $29 *$ & 35 & 43 & - & - & - \\
Based on calculations in the ERP system & 37 & 41 & 27 & - & - & - \\
Based on monitored actual lead times & 34 & 22 & 34 & - & - & - \\
Other methods & 0 & 2 & 7 & - & - & - \\
Review frequency of MRP lead times & & & & & & \\
Reviews less frequently than a year & 30 & 34 & 40 & 19 & 26 & 16 \\
Reviews roughly once a year & 37 & 35 & 33 & 41 & 48 & 47 \\
Reviews a couple of times a year & 21 & 23 & 16 & 23 & 16 & 23 \\
Reviews at every new order release & 12 & 8 & 12 & 17 & 10 & 14
\end{tabular}

Notes: $\mathrm{ML}=$ Manufacturing lead times, $\mathrm{PL}=$ Purchasing lead times; differences of lead time determination between 1993, 1999 and 2005 are tested with Chi-square statistics for row one. *Indicates cell that differs significantly $(p<0.05)$ from expected values (compared to the 1993 value) in Chi-square test. No significant difference $(p<0.05)$ was revealed between 2005 and 1999. Mann-Whitney tests of the review frequencies could not reveal any significant difference on the $p<0.05$ level between 1993 and 1999 or 1999 and 2005. Tests are conducted separately for ML and PL

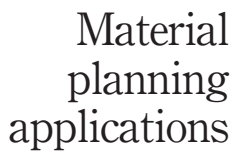

987

Table X.

Percentage of companies using various ways to determine review frequencies for MRP lead times

The proportion of companies relying on judgment and experience in determining lead times has decreased significantly from 1993 to 2005, from 43 to 29 percent. However, no significant difference in review frequency has been found between purchased items and manufactured items (Table X). In all cases, the frequency of reviewing lead times is quite low. Approximately 70 percent of the companies review their lead times once a year or less. Considering the importance of accurate lead times, this is somewhat surprising. The situation was the same in 1993, 1999, and 2005. No significantly different mode of determining lead times or review frequency of lead times was identified between small/medium- and large-sized companies in the 2005 study.

4.2.5 Planning frequency and order release. Material planning essentially means to balance supply and demand in the material flow. If the demand is greater than the supply, new replenishment orders have to be released. The frequency with which demand is compared with supply is in this context termed planning frequency. In practice this means how often material planning is carried out, in other words how often the material planning program is run in the ERP system. Less frequent material planning means planning at increased intervals, which in reality means longer lead times. It also contributes to greater uncertainty.

From the examination of how frequently companies plan, it can be seen that MRP users employ a significantly higher planning frequency than users of re-order point methods (Table XI). This difference seems logical when considering that MRP works with a much higher precision in requirements dates and due dates. MRP can thus benefit more from frequent updating of current supply and demand data. There is a general trend towards more frequent planning. For MRP the most significant increase was between 1993 and 1999, and for re-order point methods between 1999 and 2005. Currently, daily planning is the significantly most common frequency, irrespective of planning method. No significantly different planning frequency was identified between small/medium- and large-sized companies for re-order point or MRP methods in the 2005 study. 


\section{IJOPM 26,9}

988

\section{Table XI.}

Percentage of companies planning with various frequencies

\begin{tabular}{lcccccr}
\hline & ROP & ROP & ROP & MRP & MRP & MRP \\
Planning frequency & 2005 & 1999 & 1993 & 2005 & 1999 & 1993 \\
\hline Transaction oriented & 16 & 9 & 7 & 4 & 8 & 7 \\
Daily & $56^{* a}$ & $41^{*}$ & 21 & 71 & $61^{*}$ & 9 \\
Once a week & 20 & $37^{*}$ & 63 & 19 & 26 & 64 \\
Every second week or less frequently & 8 & 13 & 9 & 6 & 5 & 20 \\
Once a week or less frequently & $28^{* a}$ & $40^{*}$ & 72 & $25^{*}$ & $31^{*}$ & 84
\end{tabular}

Notes: $\mathrm{ROP}=$ Re-order point method. $\mathrm{MRP}=$ material requirements planning method. Mann-Whitney tests of the planning frequencies identified significant difference on the $p<0.05$ level between 1993 and 1999 for ROP and MRP and between 1999 and 2005 for ROP. Differences between 1993, 1999 and 2005 were also tested with Chi-square statistics for row two and for row five ( = sum of rows three and four). *Indicates cell that differs significantly $(p<0.05)$ from expected

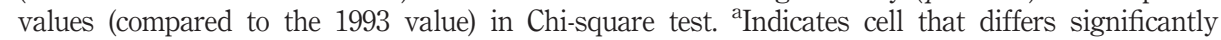
$(p<0.05)$ from expected value (compared to the 1999 value) in Chi-square test
Table XII.

Modifications before order release (percentage of companies)
The effort spent on modifying the planned order generated from the planning system before releasing the order could be a consequence of an inefficient planning process and a lack of use of the support in the ERP system. However, it could also result from the method not working well in its current conditions, thus requiring modification in order to achieve a good result. This study did not analyze the reasons for modification, but Table XII shows the extent of modifications and the types of changes to planned orders before release. MRP orders were modified to a greater extent than re-order point orders. There are several possible reasons for this. MRP generates more detailed orders, including order start date, delivery date, and order quantity, while typical re-order point orders include only the suggested order quantity. It is relatively more comprehensive to modify MRP orders, which may explain the differences between the methods in the extent of modification. MRP-generated production orders may also require modification in order to balance capacity and priority planning, for example, by advancing or postponing order starts. The only significantly differences $(p<0.05)$ identified between company sizes in the 2005 study, were between small/medium- and large-sized re-order point users where large-sized companies made fewer order changes.

\begin{tabular}{lrrrrrr}
\hline & ROP & ROP & ROP & MRP & MRP & MRP \\
& 2005 & 1999 & 1993 & 2005 & 1999 & 1993 \\
\hline Order changes before release & & & & & & \\
Few & 71 & 57 & 68 & 57 & 49 & 59 \\
A large proportion of the orders & 23 & 38 & 21 & 38 & 36 & 34 \\
Most orders & 6 & 5 & 11 & 5 & 15 & 7 \\
Type of order change & 35 & 23 & - & 33 & 39 & 53 \\
Lot size & 65 & 77 & - & 67 & 61 & 47 \\
Delivery date & & &
\end{tabular}

Notes: Mann-Whitney tests of the order change frequency identified significant difference on the $p<0.05$ level between ROP and MRP users in 2005 but not between years. Chi-square tests identified significantly different types of order changes for ROP and MRP users in 1999 and 2005 
The traditional re-order point methodology does not include functions for automatically determining delivery dates. However, this functionality is included in several ERP systems today. Nevertheless, not more than 33 percent of the respondents of the 2005 study generated delivery dates automatically from the ERP system (Table XIII). No significantly different mode of determining delivery date was identified between small/medium- and large-sized companies in the 2005 study.

4.2.6 Replanning. Three main strategies for replanning MRP orders are illustrated in Table XIV. The most common strategy is that the ERP system generates replanning suggestions but that no automatic replanning is conducted. If automatic replanning is allowed, the planner may be overruled and the additional information that the planner has and could have taken into consideration is not used. Automatic replanning is, on the other hand, more cost-efficient and faster than manual replanning. Consequently, there is a trade-off between the precision of manual planning and the speed of automatic planning. The time losses caused by manual replanning may cause significantly decreased planning performance. The findings show that the proportion of companies with a replanning capability in their ERP systems has increased significantly from 1993 to 2005. However, only a minor proportion of the companies use automatic replanning. On the other hand, too frequent adjustment of MRP plans could generate system nervousness (Tang and Grubbström, 2002). No significant difference was identified between small/medium- and large-sized companies in the 2005 study.

\subsection{Concluding discussion}

The main findings and discussion of the use and modes of applying material planning methods are summarized in Table XV.

\begin{tabular}{lccr}
\hline & ROP & ROP & ROP \\
Determination of delivery dates in ROP & 2005 & 1999 & 1993 \\
\hline $\begin{array}{l}\text { Manually adding lead time to today's date } \\
\text { Generated from the ERP system }\end{array}$ & 36 & 44 & 40 \\
$\begin{array}{l}\text { Determined based on additional information from } \\
\text { the ERP }\end{array}$ & 33 & 15 & 29 \\
Other & 28 & 36 & 33 \\
\end{tabular}

Note: Chi-square tests could not reveal any significantly $(p<0.05)$ different determination strategy between 1993, 1999 and 2005

\section{Material planning applications}

989

\begin{tabular}{lccr}
\hline Re-planning in MRP & 2005 & 1999 & 1993 \\
\hline No re-planning ability in the ERP system & $20^{*}$ & $27^{*}$ & 41 \\
The ERP system generates re-planning suggestions & 62 & 63 & 50 \\
The ERP system conducts automatic re-planning & 18 & 10 & 9
\end{tabular}

Notes: Differences between 1993, 1999 and 2005 are tested with Chi-square statistics for row one. *Indicates cell that differs significantly $(p<0.05)$ from expected values (compared to the 1993 value) in Chi-square test. No significant $(p<0.05)$ difference was identified between 2005 and 1999

Table XIV. Re-planning of MRP
Determination of delivery of delivery dates in ROP (percentage of companies) in 
IJOPM

26,9

990

Table XV.

Summary of findings and discussion

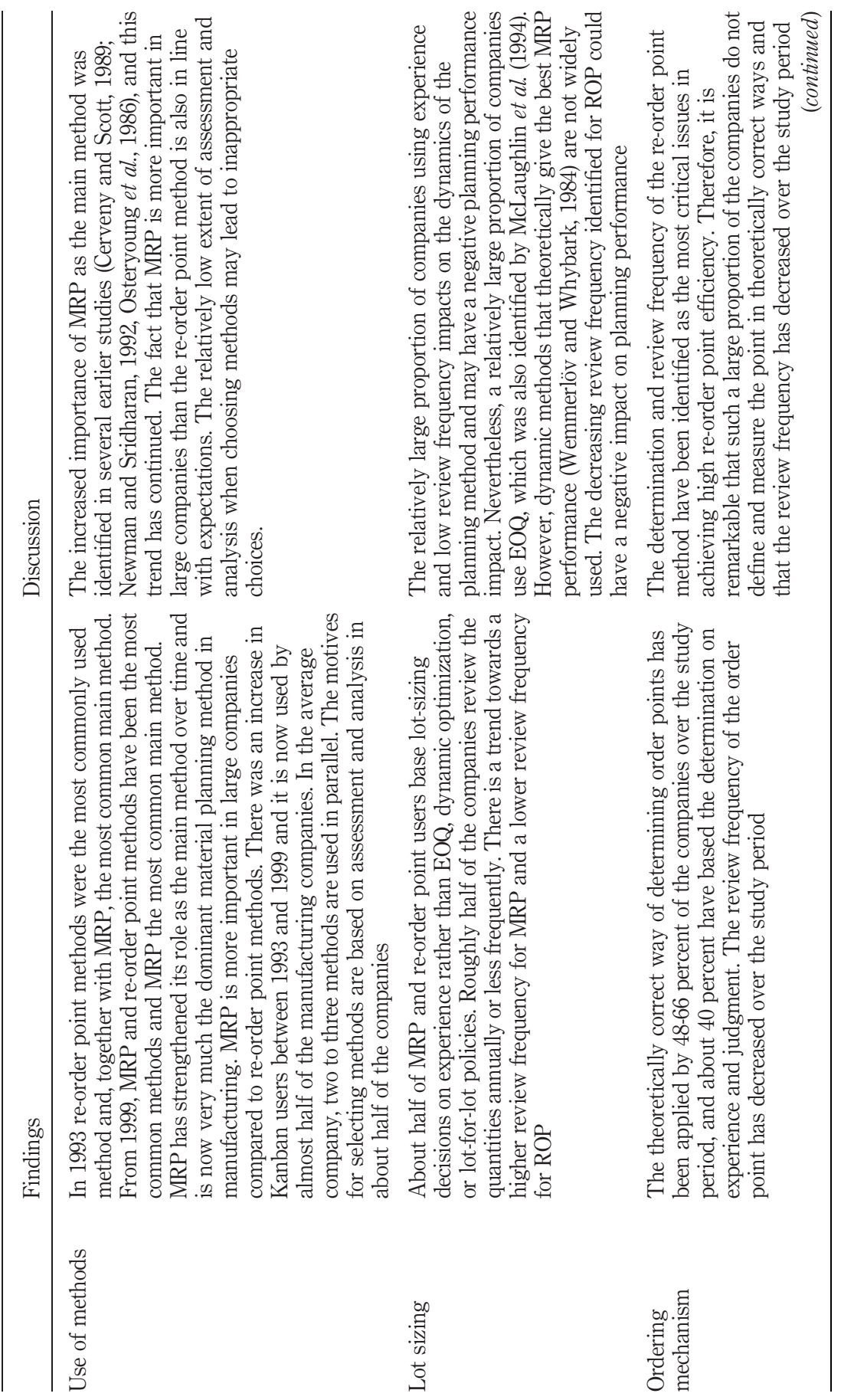




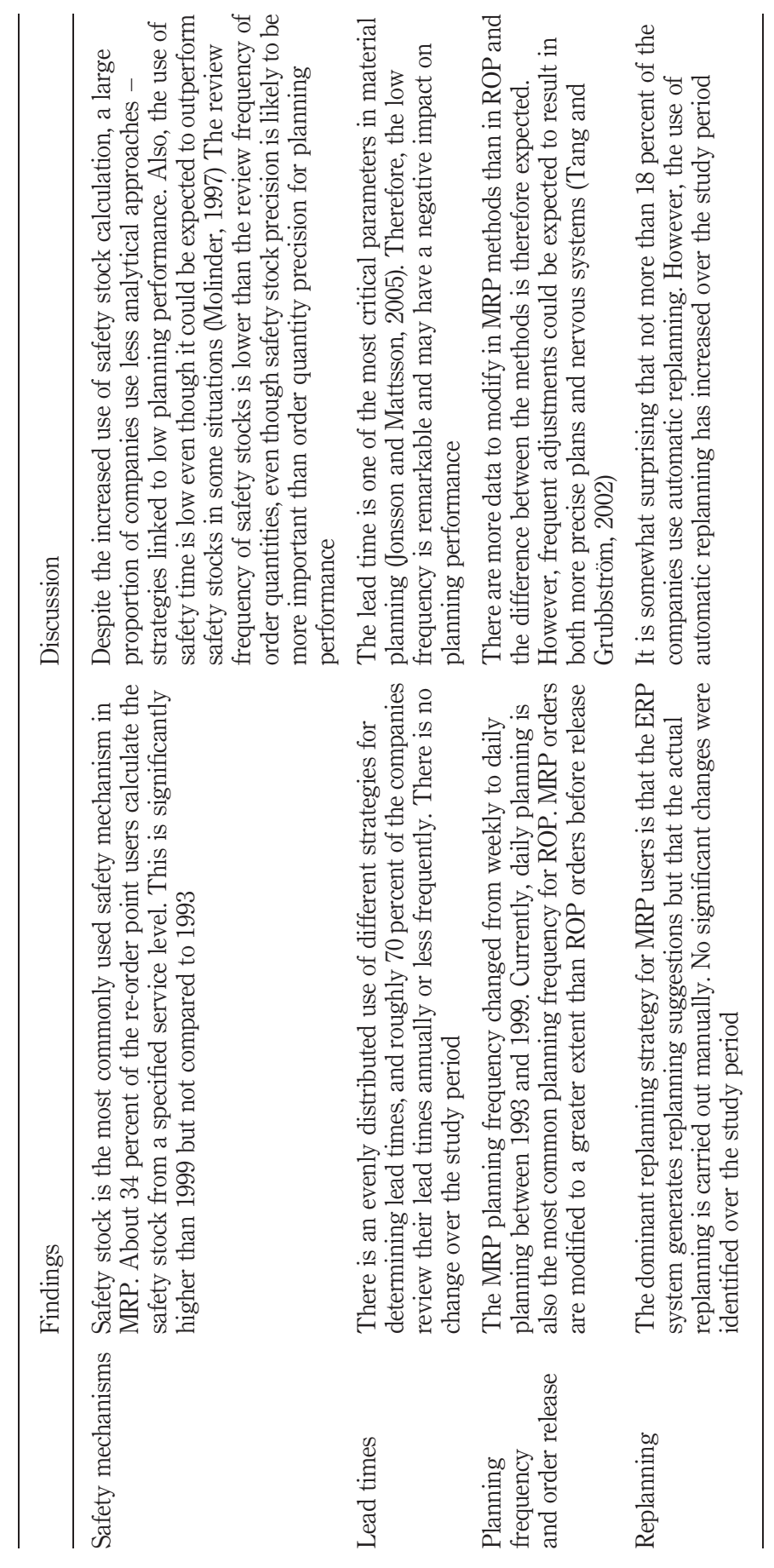

991

Table XV. 
IJOPM

26,9

992

\section{Conclusions and future research}

\subsection{Conclusions}

From the results of the study, we can conclude that MRP is the most common material planning method and that its position has strengthened since the 1990s. Several of the characteristic modes of applying planning methods may have a negative performance impact. Below is a list of modes of application found in the average company that may have a negative impact on performance:

- There is a decreasing review frequency of order quantities in the re-order point method. The corresponding review frequency for MRP is increasing, however.

- About 40 percent of re-order point users do not define the re-order point as the demand during lead time plus a safety stock, but as an experience-based fixed quantity. The proportion of companies reviewing the order point annually or less frequently is increasing.

- The majority of re-order point users also use MRP, but only a small proportion use MRP to generate demand data for the re-order point method.

- Less than 50 percent review safety stocks more than once a year. For re-order point users, order quantities are reviewed more frequently than safety stocks even though accurate safety stocks are likely to have a greater performance impact than accurate order quantities.

- MRP users use safety stocks to a significantly greater extent than safety times even though safety times may be more accurate.

- A decreasing proportion of companies rely on experience and judgment when determining lead times, but only 70 percent review lead times annually or more frequently.

- The proportion of companies with replanning capability in their ERP systems has increased, but only a minor portion of the companies use automatic replanning.

The following is a list of identified specific modes of application that should result in a positive impact on planning performance:

- An increasing proportion of companies calculate safety stocks from specified service levels.

- Compared to 1999, a greater proportion of companies calculate the re-order point as the demand during lead time plus a safety stock.

- A decreasing proportion of companies rely on experience and judgment when determining lead times in MRP.

- There is a trend towards more frequent material planning. Today, daily planning is most common, both for MRP and ROP.

It could thus be concluded that a common way of determining parameters such as order quantities and safety stocks is by general judgment and experience. Only a minority of companies applied formal calculations and optimizations. Parameters used in the material planning methods are reviewed rather infrequently, typically once a year or less in over half of the companies. For re-order point methods, there is a general trend towards less frequent reviewing. The planning frequency, i.e. how often material planning is carried out, increased significantly during the 1990s. In 1993, once a week 
was the most typical planning frequency in manufacturing companies. Planning once a day is a more representative planning frequency today, especially for MRP.

This study has a number of managerial implications. It identifies that the frequency of reviewing planning variables and parameters is relatively low in industry, and that in most situations it should be increased. Therefore, more user-friendly and efficient software applications, for example, tools that easily allow automatic revision of planning parameters, need to be developed and implemented. The study also suggests that the general level of knowledge of planning and control methods in the industry is rather low, and that it most likely needs be improved in order to achieve better use and performance of the planning methods. Further, the findings could serve as guidelines when designing and developing training and education programs in manufacturing planning and control. It could also function as a benchmark for companies looking for methods and applications with satisfied users.

\subsection{Future research}

Several companies have problems in successfully implementing ERP systems and applying material planning methods to their processes. Therefore, it is important to carry out research that improves our knowledge about successful and unsuccessful uses of planning systems and methods.

Very few studies similar to the present one have been conducted in the area of material planning and manufacturing planning and control. Therefore, it is not possible to compare our findings. It would, nevertheless, be interesting to compare the results of this study with future studies in other countries and industries.

The longitudinal analysis conducted in this paper contain some potential weaknesses due to the lack of perfectly homogeneous samples and since the analyses are not restricted to focused fields, like a specific industry, a specific company size, a specific manufacturing process, a specific planning environment, etc. Only few differences in method usage and modes of applying the methods were, however, identified between company sizes and different industries, which verify the appropriateness of the samples and analyses. Studies looking at method usage in more restricted fields than conducted here would be valuable in order to further validate the findings of this study and to gain deeper knowledge about the method usage in specific situations. The study did not, for example, analyze the appropriateness of the planning methods in various planning environments (e.g. manufacturing of complex customer products vs repetitive mass production), although the planning methods are more or less applicable to various planning environments. Further, the study did not differentiate between material planning of items in manufacturing companies and products and spare parts in distribution companies. A contingency approach could be applied to the material-planning problem. Such an approach could become an important managerial support when choosing and applying material planning methods.

\section{References}

Anderson, J., Schroeder, R., Tupy, S. and White, E.(1982), "Material requirements planning systems", Production and Inventory Management Journal, Vol. 23 No. 4, pp. 51-67.

Bendoly, E. and Jacobs, R. (2004), "ERP architectural/operational alignment for order-processing performance", International Journal of Operations \& Production Management, Vol. 24 No. 1, pp. 99-117. 
IJOPM

26,9

994
Benton, W.C. (1991), "Safety stock and service levels in periodic review inventory systems", The Journal of the Operational Research Society, Vol. 42 No. 12, pp. 198-1095.

Berry, W. and Hill, T. (1992), "Linking systems to strategy", International Journal of Operations \& Production Management, Vol. 12 No. 10, pp. 3-15.

Bryman, A. (2004), Social Research Methods, Oxford University Press, Oxford.

Cerveny, R. and Scott, L. (1989), “A survey of MRP implementation”, Production and Inventory Management Journal, Vol. 30 No. 3, pp. 31-5.

Code, D. (1993), “A survey of UK manufacturing control over the past ten years", Production and Inventory Management Journal, Vol. 34 No. 2, pp. 53-6.

Davis, E. (1975), "A look at the use of production-inventory control techniques: past and present", Production and Inventory Management, Vol. 16 No. 4, pp. 1-19.

Enns, S. (1999), “The effect of batch size selection on MRP performance”, Computers \& Industrial Engineering, Vol. 37, pp. 15-19.

Ford, N., Bradbart, D., Ledbetter, W. and Cox, J. (1987), "Use of operations research in production management", Production and Inventory Management Journal, Vol. 28 No. 3, pp. 59-63.

Gianque, W.C. and Sawaya, W.J. (1992), "Strategies for production control", Production and Inventory Management Journal, Vol. 33 No. 3, pp. 36-41.

Haddock, J. and Hubicki, D. (1989), "Which lot-sizing techniques are used in material requirements planning?", Production and Inventory Management Journal, Vol. 30 No. 3, pp. 29-35.

Hair, J., Anderson, R., Tatham, R. and Black, W. (1998), Multivariate Data Analysis, Prentice-Hall, London.

Huang, S-T. (2000), "Research on changes of total cost of dynamic economic lot size", Production Planning \& Control, Vol. 11 No. 1, pp. 54-61.

Im, J. (1989), "How does Kanban work in American companies?", Production and Inventory Management Journal, Vol. 30 No. 4, pp. 22-4.

Jacobs, R. and Bendoly, E. (2003), "Enterprise resource planning: developments and directions for operations management research", European Journal of Operational Research, Vol. 146, pp. 233-40.

Jonsson, P. and Mattsson, S-A. (2002), "The selection and application of material planning methods", Production Planning \& Control, Vol. 13 No. 5, pp. 438-50.

Jonsson, P. and Mattsson, S-A. (2003), "The implication of fit between planning environments and manufacturing planning and control methods", International Journal of Operations \& Production Management, Vol. 23 No. 8, pp. 872-900.

Jonsson, P. and Mattsson, S-A. (2005), "Operational strategies for achieving material planning efficiency", Proceedings of the Annual EUROMA Conference 2005, Budapest.

Laforge, L. and Sturr, V. (1986), "MRP practices in a random sample of manufacturing firms", Production and Inventory Management Journal, Vol. 27 No. 3, pp. 129-36.

Ledbetter, W. and Cox, J. (1977), "Operations research in production management", Production and Inventory Management Journal, Vol. 18 No. 3, pp. 84-92.

McLaughlin, C., Vastag, D. and Whybark, C. (1994), "Statistical inventory control in theory and practice", International Journal of Production Economics, Vol. 35 Nos 1/3, pp. 161-70.

Mattsson, S-A. (1994), Materialplaneringsmetoder $i$ svensk industri, Institutet för transportekonomi och logistik, Högskolan i Växjö, Växjö.

Molinder, A. (1997), "Joint optimization of lot-sizes, safety stocks and safety lead times in an MRP system”, International Journal of Production Research, Vol. 35 No. 4, pp. 983-94. 
Moras, R. and Dieck, A. (1992), "Industrial applications of just-in-time: lessons to be learned", Production and Inventory Management Journal, Vol. 33 No. 3, pp. 25-9.

Newman, W. and Sridharan, V. (1992), "Manufacturing planning and control: is there one definite answer?", Production and Inventory Management Journal, Vol. 33 No. 1, pp. 50-4.

Newman, W. and Sridharan, V. (1995), "Linking manufacturing planning and control to the manufacturing environment”, Integrated Manufacturing Systems, Vol. 6 No. 4, pp. 36-42.

Olhager, J. and Seldin, E. (2004), "Supply chain management survey of Swedish manufacturing firms", International Journal of Production Economics, Vol. 89, pp. 353-61.

Osteryoung, J., Nosari, E., McCarty, D. and Reinhart, W. (1986), "Use of the EOQ model for inventory analysis", Production and Inventory Management Journal, Vol. 14 No. 3, pp. 39-46.

Plenert, G. (1999), "Focusing material requirements planning (MRP) towards performance", European Journal of Operations Research, Vol. 119, pp. 91-9.

Roberts, H.J. and Barrar, P.R.N. (1992), "MRP II implementation: key factors for success", Computer-Integrated Manufacturing Systems, Vol. 5, pp. 31-8.

Rabinovich, E. and Evers, P. (2002), "Enterprise-wide adoption patterns of inventory management practices and information systems", Transportation Research Part E, Vol. 38, pp. 389-404.

Siegel, S. and Castellan, N.J. (1988), Nonparametric Statistics for the Behavioral Sciences, McGraw-Hill, New York, NY.

Schroeder, D., Congden, S. and Gopinath, C. (1995), "Linking competitive strategy and manufacturing process technology", Journal of Management Studies, Vol. 32 No. 2, pp. 163-89.

Tang, O. and Grubbström, R. (2002), "Planning and replanning the master production schedule under demand uncertainty", International Journal of Production Economics, Vol. 78, pp. 323-34.

Vollmann, T., Berry, W., Whybark, C. and Jacobs, R. (2005), Manufacturing Planning and Control for Supply Chain Management, McGraw-Hill, New York, NY.

Wemmerlöv, U. and Whybark, D. (1984), "Lot sizing under uncertainty in a rolling schedule environment", International Journal of Production Research, Vol. 22 No. 3, pp. 467-84.

White, R., Pearson, J. and Wilson, J. (1999), "JIT manufacturing: a survey of implementations in small and large manufacturers", Management Science, Vol. 45, pp. 1-15.

Whybark, C. and Williams, J. (1976), "Material requirements planning under uncertainty", Decision Sciences, Vol. 7 No. 4.

Zhao, X. and Lee, T. (1993), "Freezing the master production schedule under demand uncertainty", Journal of Operations Management, Vol. 11, pp. 185-205.

Zijm, W. and Buitenhek, R. (1996), “Capacity planning and lead time management”, International Journal of Production Economics, Vol. 46/47, pp. 165-79.

\section{Corresponding author}

Patrik Jonsson can be contacted at: Patrik.jonsson@chalmers.se

\footnotetext{
To purchase reprints of this article please e-mail: reprints@emeraldinsight.com
} Or visit our web site for further details: www.emeraldinsight.com/reprints 